\title{
Desain dan Konstruksi Prototype KIT Proyek STEM Sebagai Media Pembelajaran IPA SMP Secara Daring pada Topik Aplikasi Listrik Dinamis
}

\author{
Z. Zulirfan ${ }^{1 *}$, Y. Yennita ${ }^{2}$, M. Rahmad ${ }^{3}$, Agus Purnama $^{4}$ \\ 1. Program Studi Pendidikan Fisike, Universitas Riau \\ ${ }^{2,3,4}$ Program Studi Magister Pendidikan IP A, Universitas Riau \\ *Correspondence Address: zulirfan@lecturer.unri.ac.id
}

\begin{abstract}
The Covid-19 pandemic has a significant impact on the quality of the science learning process. Online learning restricts students from directly interacting with science tools and materials. It takes effort from science educators to facilitate students in direct learning activities (hands on activity). This research is an attempt to facilitate students in learning by doing activities. In general, this study aims to provide a STEM project KIT that students can use in online-based junior high school science learning. Based on the results of the study in the analysis phase, the researcher has identified and designed three simple STEM projects that can be built as applications for the Dynamic Electricity concept. The three STEM projects are the Fruit Electric Energy Content Exploration Project, the Flood Alarm Model Making Project, and the Micro-Hydro Power Plant Model Building Project. For the purposes of these three student STEM projects, the researcher has built a KIT with stages including: tool and material selection, assembly, and expert validation. This research has produced a prototype of the Dynamic Electricity Application STEM Project KIT which is declared valid and feasible as a medium for junior secondary science learning, both for online and offline learning.
\end{abstract}

Kata kunci: dynamic electrical applications, design and validation, STEM project KITs, online science learning

\begin{abstract}
ABSTRAK
Pandemi Covid-19 memberikan dampak yang signifikan terhadap mutu proses pembelajaran IPA. Pembelajaran daring membatasi siswa sehingga tidak dapat berinteraksi secara langsung dengan alat-alat dan bahan IPA. Perlu usaha dari para pendidik IPA untuk memfasilitasi siswa dalam aktivitas belajar secara langsung (hands on activity). Penelitian ini merupakan salah satu usaha untuk memfasiltasi siswa dalam aktivitas learning by doing tersebut. Secara umum penelitian bertujuan menyediakan perangkat KIT proyek STEM yang dapat digunakan siswa dalam pembelajaran IPA SMP berbasis daring. Berdasarkan hasil kajian pada fasa analisis, peneliti telah mengidentifikasi dan mendesain tiga proyek STEM sederhana yang dapat dibangun sebagai aplikasi konsep Listrik Dinamis. Ketiga proyek STEM tersebut adalah Proyek Eksplorasi Kandungan Energi Listrik Buah-buahan, Proyek Pembuatan Model Alarm Banjir, dan Proyek Pembuatan Model Pembangkit Listrik Mikrohidro. Untuk keperluan ketiga proyek STEM siswa tersebut, peneliti telah membangun KIT dengan tahapan meliputi: pemilihan alat dan bahan, perakitan, dan validasi pakar. Penelitian ini telah menghasilkan sebuak prototype KIT Proyek STEM Aplikasi Listrik Dinamis yang dinyatakan sah dan layak sebagai media pembelajaran IPA SMP, baik untuk pembelajaran daring maupun luring.
\end{abstract}

Kata kunci: aplikasi listrik dinamis, desain dan validasi, KIT proyek STEM, pembelajaran IPA daring 


\section{PENDAHULUAN}

Persaingan dalam ekonomi global dalam abad 21 dan revolusi industry 4,0 perlu dipersiapkan tenaga kerja yang memiliki kemampuan berpikir kritis dan kreatif serta menguasai ICT. Pengajaran dengan pendekatan STEM telah menjadi semakin penting dalam persaingan ekonomi global abad 21(Kennedy, et al. 2014). Sayangnya, kemampuan berpikir tingkat tinggi anak-anak Indonesia masih rendah seperti hasil kajian TIMSS 2018 dan beberapa kajian lainnya. Kemampuan berpikir rata-rata siswa kita baru pada tahap low-order thinking skills (Murnawianto, et al. 2017). Pada pengajaran sains, salah satu pendekatan yang dipandang mampu meningkatkan kemampuan berpikir kritis dan kreatif untuk menghadapi tantangan abad-21 adalah pendekatan STEM (Nugroho, et al. 2019). Pendekatan STEM (science-technology-engineering-math) ini mengintegrasikan antara sains, teknologi, rekayasa, dan matematika (Gonzalez \& Kuenzi, 2012). Kajian menunjukkan bahwa guru sains mempunyai persepsi positif terhadap penerapan STEM dalam pembelajaran (Bozkurt \& Ercan, 2016).

Dewasa ini, bekerja dan belajar bisa dari mana saja dan kapan saja. Karena itu, pembelajaran tidak lagi dibatasi oleh bangunan sekolah, ruang kelas, dan laboratorium. Blended learning (BL) adalah konsep inovatif yang mengintegrasikan keunggulan pengajaran tradisional di kelas dan pembelajaran yang didukung teknologi informasi online (Lalima \& Lata, 2017). Sementara itu, pembelajaran yang dimediasi oleh perpaduan komputer jaringan dan tatap muka (blended) dapat menciptakan pengalaman belajar yang lebih efektif, meningkatkan akses dan fleksibilitas, atau mengurangi biaya belajar (Bryan \& Volchenkova, 2016). Di samping itu pengembangan BL adalah pada bagaimana mendesain ulang strategi pembelajaran dan mencari cara paling efektif untuk menyampaikan materi pembelajaran secara online dan juga penggunaan teknologi yang efektif (Poon Poon, 2013)

Pelajaran sains berisikan kerja ilmiah yang mewajibkan siswa mengalami proses saintifik secara langsung. Di samping itu pembelajaran sains yang mengintegrasikan sains, teknologi, rekayasa, dan matematika melalui STEM memberikan manfaat bagi siswa dalam mengembangkan kemampuan berpikir kritis dan kemampuan berpikir kreatif yang diperlukan dalam era revolusi industri 4.0. Pembelajaran sains dengan pendekatan STEM merupakan hand on activity. Siswa secara individu maupun kelompok mengerjakan proyek sains sederhana yang berkaitan dengan konsep yang sedang atau sudah dipelajari. Namun sayangnya, pembelajaran STEM sampai hari ini belum optimal dilaksanakan. Salah satu persoalan yang dihadapi dalam mengimplementasikan pendidikan STEM adalah kurangnya fasilitas laboratorium dan media pengajaran, serta siswa yang belum terlatih dalam melaksanakan aktivitas proyek (Ejiwale, 2013).

Pada masa bencana seperti wabah penyakit Covid-19 yang sedang berlangsung dan bencana kabut asap karhutla yang selalu melanda Provinsi Riau, interaksi langsung guru dan siswa dalam pembelajaran di kelas atau di laboratorium sekolah menjadi terbatas. Karena siswa harus tetap belajar, maka pembelajaran sains berbasis daring merupakan satu alternatif. Agar siswa tetap dapat belajar sains melalui proyek STEM secara daring, maka perlu disiapkan media pembelajaran. Media pembelajaran dengan pendekatan STEM berupa KIT yang menyediakan alat dan bahan untuk keperluan proyek STEM siswa. Sebagai media pembelajaran, KIT proyek STEM ini haruslah memenuhi persyaratan valid dan praktis digunakan siswa dalam mengerjakan proyek STEM mereka. Sementara itu, untuk mengontrol, dan mendampingi siswa dalam melaksanakan proyek STEM mereka, aplikasi pembelajaran daring dapat dimanfaatkan.

Media pembelajaran harus memenuhi kriteria: visible, interesting, simple, useful, accurate, legitimate, dan structure (Sudjana \& Rivai (2019). Visible berarti media pembelajaran harus memiliki keterbacaan bagi siswa dan media pembelajaran harus mampu menarik perhatian siswa (interesting) sehingga siswa terdorong untuk mencari tahu pesan yang ingin disampikan media pembelajaran tersebut. Sementara itu, media pembelajaran harus menampilkan kesederhanaan (simple) sehingga efisien dan praktis. Media pembelajaran harus memberikan manfaat dalam 
pencapaian tujuan pembelajaran. Accurate, bermakna bahwa media pembelajaran harus benarbenar sesuai dengan materi pembelajaran. Legitimate, bermakna bahwa media pembelajaran sah digunakan untuk mencapai tujuan pembelajaran. Structured, artinya media pembelajaran tak terpisahkan dari materi pembelajaran. Sebagai media pembelajaran, KIT proyek STEM harus memenuhi kriteria-kriteria tertentu untuk menggunakan kriteria proyek STEM sebagai berikut: secara desain berkualitas, memiliki daya tarik visual, interaktif, koherensi dengan kurikulum, dan menggabungkan unsur-unsur STEM (Ismail, et al. 2016)

Pada fasa design dan develop ini, peneliti mengajukan dua pertanyaan penelitian yang akan dijawab melalui proses penelitian. Pertanyaan tersebut adalah (1) seperti apakah desain protoype KIT Proyek STEM Aplikasi Listrik Dinamis yang dapat digunakan sebagai media pembelajaran IPA SMP baik secara daring maupun luring?; dan (2) seperti apakah KIT proyek STEM Aplikasi Listrik Dinamis yang valid sehingga layak digunakan untuk pembelajaran IPA SMP secara daring maupun luring?

Sesuai dengan pertanyaan penelitian di atas, maka tujuan penelitian ini adalah mendesain dan membangun KIT proyek STEM Aplikasi Listrik Dinamis sebagai media pembelajaran IPA SMP. Mendesains KIT yang dimaksud meliputi proses pembuatan skema rancangan dan pemilihan alat dan bahan yang sesuai, sedangkan membangun KIT meliputi proses perakitan alat dan bahan menjadi KIT proyek dan melakukan validasi pakar terhadap draft prototype KIT yang telah dirakit. Artikel ini akan dijelaskan proses desain beserta hasil desain dan proses perkaitan serta proses dan hasil validasi pakar.

\section{METODOLOGI}

Penelitian pengembangan ini menggunakan desain pengembangan sistem instruksional pendekatan ADDIE (Analysis, Design, Develop, Implement, Evaluate). Penelitian ini mengadaptasi model ADDIE dari Branch (2009). Hasil penelitian pada fasa analisis telah dilaporkan pada publikasi terdahulu (Zulirfan, et al. 2020).

Berdasarkan rekomendasi fasa analisis, pada fasa ini kami melakukan desain prototype KIT STEM untuk pembelajaran IPA pada topik listrik dinamis. Teridentifikasi 4 proyek STEM yang dapat dikerjakan siswa di rumah diantaranya: penelitian kandungan energi listrik berbagai jenis buah-buahan, model pembangkit listrik mikrohidro, model alarm banjir sederhana, dan model lampu jalan otomatis. Setelah proses desain, selanjutnya dilakukan perakitan komponenkomponen KIT. Setelah proses perakitan, dilakukan uji coba laboratorium untuk memastikan bahwa KIT sudah menunjukkan fungsinya. Agar KIT memenuhi ketentuan layak sebagai media pembelajaran, maka dilakukan proses validasi. Validasi dilakukan dengan meminta pendapat dan penilaian pakar pendidikan IPA terhadap draft KIT proyek STEM. Instrumen penilaian pakar terhadap prototype KIT proyek STEM dalam penelitian ini dikembangkan dengan mengadaptasi aspek-aspek proyek STEM menurut (Ismail, et al. 2016; Sudjana \& Rivai, 2019). Profil instrumen penilaian pakar ditunjukkan oleh Tabel 1.

Tabel 1. Aspek dan Item Penilaian Pakar Terhadap Prototype KIT Proyek STEM Rumahan

\begin{tabular}{|c|c|c|}
\hline No & Aspek & Item Penilaian \\
\hline 1 & $\begin{array}{l}\text { Koherensi dengan } \\
\text { kurikulum }\end{array}$ & $\begin{array}{ll}\text { - } & \text { KIT sesuai untuk siswa tingkat SMP } \\
\text { - } & \text { KIT mengintegrasikan elemen-elemen STEM } \\
\text { - } & \text { Proyek STEM mendukung pencapaian tujuan pembelajaran IPA } \\
\text { - } & \text { KIT sesuai untuk keperluan proyek yang berkaitan aplikasi } \\
& \text { Listrik Dinamis } \\
\text { - } & \text { Proyek STEM meningkatkan kemampuan berpikir tingkat tinggi }\end{array}$ \\
\hline 2 & Interaktif & $\begin{array}{l}\text { - KIT memungkinkan siswa membuat rancangan dan konstruksi } \\
\text { proyek yang berbeda dari petunjuk } \\
\text { - } \quad \text { KIT menimbulkan keinginan untuk merancang proyek lainnya }\end{array}$ \\
\hline
\end{tabular}




\begin{tabular}{|c|c|c|}
\hline No & Aspek & Item Penilaian \\
\hline & & $\begin{array}{l}\text { - Proyek dapat dikerjakan bersama-sama dalam kelompok belajar } \\
\text { di sekolah } \\
\text { - Proyek STEM dapat dikerjakan bersama-sama anggota keluarga } \\
\text { di rumah }\end{array}$ \\
\hline 3 & Fleksibilitas & $\begin{array}{ll}\text { - } & \text { Proyek STEM siswa tidak memerlukan tempat khusus } \\
\text { - } & \text { Proyek dapat dilaksanakan kapan saja dan berulang-ulang } \\
\text { - } & \text { Komponen KIT dapat dipakai untuk beberapa proyek berbeda } \\
\text { - } & \text { Proyek STEM dapat dikerjakan di rumah dengan pembimbingan } \\
& \text { guru secara daring }\end{array}$ \\
\hline 4 & Daya tarik visual & $\begin{array}{ll}\text { - } & \text { Komponen KIT menarik perhatian siswa } \\
\text { - } & \text { KIT menghasilkan proyek yang menarik } \\
\text { - } & \text { Proyek yang dikerjakan bermanfaat bagi siswa } \\
\text { - } & \text { Rangkaian listrik yang dibuat menggunakan KIT bersifat } \\
\text { sederhana sehingga mudah diikuti }\end{array}$ \\
\hline 5 & Kesederhanaan & $\begin{array}{ll}\text { - } & \text { Komponen KIT sederhana dari bentuk dan cara kerja } \\
\text { - } & \text { Komponen KIT berharga relatif murah } \\
\text { - } & \text { Komponen KIT mudah didapat }\end{array}$ \\
\hline 6 & Keamanan & $\begin{array}{ll}\text { - } & \text { KIT tidak memiliki komponen yang mudah pecah } \\
\text { - } & \text { KIT tidak memiliki bahan yang beracun atau mudah terbakar } \\
\text { - } & \text { KIT tidak menggunakan listrik tegangan tinggi }\end{array}$ \\
\hline 7 & Kemudahan & $\begin{array}{ll}\text { - } & \text { Perakitan KIT dalam proyek efisien dari segi waktu } \\
\text { - } & \text { Mudah dalam bongkar-pasang proyek } \\
\text { - } & \text { KIT mudah dikemas kembali setelah pemakaian } \\
\end{array}$ \\
\hline
\end{tabular}

Pada setiap item penilaian, pakar memberikan pendapat dengan skala: 4, apabila sangat setuju; 3, apabila setuju; 2, apabila tidak setuju dan 1, apabila sangat tidak setuju. Disamping memberikan penilaian, pakar juga diminta memberikan saran perbaikan terutama pada item-item yang dinilai 1 dan 2. Peneliti akan merevisi draft KIT sesuai dengan saran perbaikan pakar. Apabila semua item penilaian KIT dinilai valid oleh semua pakar, maka prototype KIT Proyek STEM Rumahan dinyatakan sah dan layak digunakan sebagai media pembelajaran IPA secara daring.

Pada artikel ini peneliti melaporkan proses dan hasil riset pada fase desain dan develop terhadap prototype KIT proyek STEM ini. Fase implementasi dan evaluasi akan dilaporkan setelah kedua fase riset tersebut selesai dilaksanakan.

\section{TEMUAN DAN PEMBAHASAN}

\section{Fasa Design}

Berdasarkan fasa analisis, peneliti telah mengidentifikasi tiga proyek STEM pada topik pembelajaran IPA Listrik Dinamis yang dapat dikembangkan. Ketiga proyek tersebut adalah: Proyek Eksplorasi Kandungan Energi Listrik Buah-buahan, Proyek Model Alarm Banjir, dan Proyek Model Pembangkit Listrik Mikrohidro. Desain dari ketiga proyek tersebut ditunjukkan pada Gambar 1.

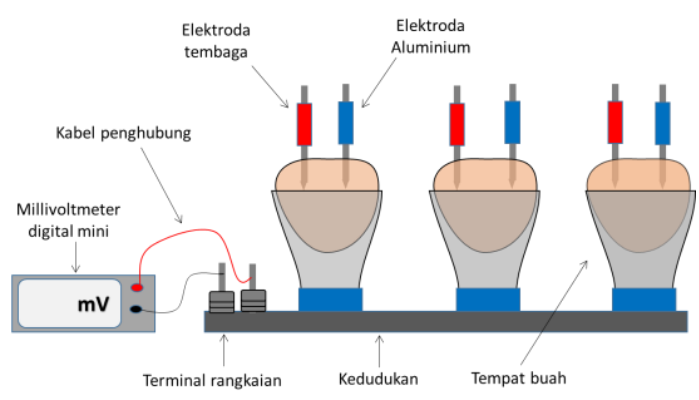

Gambar 1. Desain Proyek STEM Eksplorasi Kandungan Energi Listrik Buah-buahan 
Gambar 1 menunjukkan desain Proyek STEM Eksplorasi Energi Listrik Buah-buahan. Proyek ini bertujuan untuk membangun pemikiran kritis dan kreatif siswa dalam memanfaatkan sumber daya alam yang ada di sekitar mereka dengan menerapkan elemen-elemen STEM. Buahbuahan paling dekat dengan kehudpan sehari-hari siswa. Pada pembelajaran, tujuan proyek ini adalah (1) mengukur dan membandingkan energi listrik berbagai macam buah-buahan yang ada di sekitar kita, (2) menyelidiki parameter dari buah yang menentukan kadar energi yang dimiliki, (3) merangkai GGL buahan-buahan untuk menghasilkan energi listrik dengan besar tertentu. Kegiatan proyek tersebut dimulai dari (1) menelusuri informasi di internet (elemen Technology), (2) membuat skema pengukuran dan memilih alat dan bahan yang sesuai (elemen Engineering), (3) menyiapkan beberapa jenis buah-buahan yang diprediksi memiliki kandungan energi (elemen Science), (4) merangkai komponen KIT (elemen Science \& Technology), (5) mengukur nilai kandungan energi listrik (Math, Science \& Technology), (6) merangkai dan mengukur GGL buah buahan (elemen Science).

Proyek STEM Model Alarm Banjir secara umum bertujuan untuk membangun sikap kepedulian siswa terhadap bencana alam, melatih siswa agar terampil menerapkan konsep listrik dinamis dalam produk teknologi sederhana, serta mengintegrasikan elemen-elemen STEM dalam proyek. Pada pembelajaran, tujuan proyek ini adalah (1) merancang skema rangkaian, merakit, dan menguji fungsi alarm banjir dengan indikator lampu, (2) merancang skema rangkaian, merakit, dan menguji fungsi alarm banjir dengan dengan indikator buz:er, dan (3) membuat rancangan sendiri alarm banjir yang akan dipasang di sungai untuk mewaspadai naiknya air sungai. Desain model alarm banjir sederhana ditunjukkan pada Gambar 2.

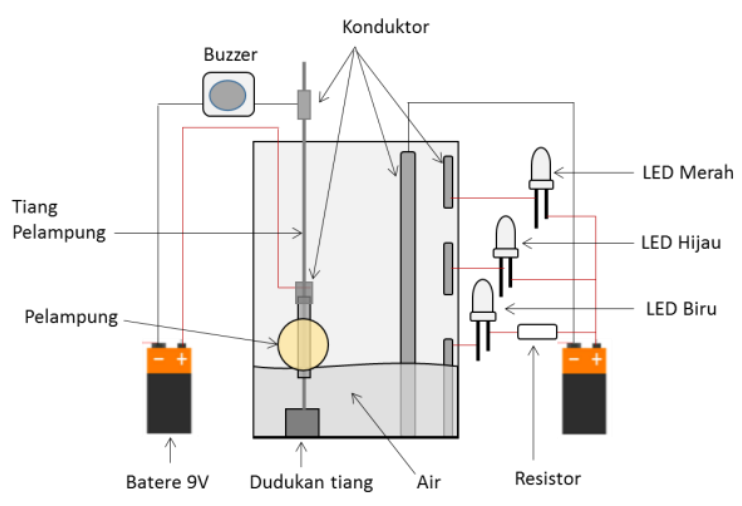

Gambar 2. Desain Proyek STEM Model Alarm Banjir

Desain dalam Gambar 2 menunjukkan ada dua sistem alarm. Sistem tersebut adalah alarm dengan indikator lampu. Lampu LED biru menyatakan bahwa permukaan air masih rendah sehingga keadaan aman, LED hijau menyatakan permukaan air sudah naik pada level sedang, sehingga keadaan pada level hati-hati, dan LED merah menyatakan bahwa level air sudah tinggi dan keadaan berbahaya. Sistem yang kedua adalah alarm dengan indikator bunyi buzzer. Ketika permukaan air naik pada level berbahaya, buzzer berbunyi.

Kegiatan proyek STEM Model Alarm Banjir yang dilakukan siswa mulai dari (1) merancang skema alarm (Science \& Engineering); (2) memilih alat dan bahan yang sesuai (Science \& Technology); (3) merakit dan menguji (Math, Science \& Engineering);(4) mencari informasi di internet tentang alarm banjir sesungguhnya (Technology); dan (5) merancang skema pemasangan alarm sederhana untuk mendeteksi kenaikan permukaan air di sungai (Engineering).

Sementara itu, Proyek STEM Model Pembangkit Mikrohidro bertujuan untuk membangun sikap peduli siswa terhadap energi, melatih kemampuan berpikir kreatif dan inovatif dalam menerapkan konsep sains. Pada pembelajaran, proyek ini bertujuan untuk (1) merancang skema model; (2) merakit model' (3) menguji fungsi model pembangkit listrik mikrohidro; dan (4) merancang skema pemasangan pembangkit listrik mikrohidro di sungai, atau di air terjun skala 
kecil. Sama halnya dengan proyek kedua, kegiatan proyek STEM Model Pembangkit listrik mikrohidro siswa mulai dari (1) merancang skema pembangkit listrik mikrohidro (Science \& Engineering); (2) memilih alat dan bahan yang sesuai (Science \& Technology); (3) merakit dan menguji (Science \& Engineering). Mengukur tegangan listrik yang dihasilkan sebagai variasi ketinggian sumber air (Science \& Math) (4); mencari informasi di internet tentang pemanfaatan pembangkit listrik mikrohidro (Technology); dan (5) merancang skema pemasangan pembangkit listrik mikrohidro di sungai berarus, atau air terjun sekala kecil. Desain pembangkit listrik mikrohidro ditunjukkan oleh Gambar 3.

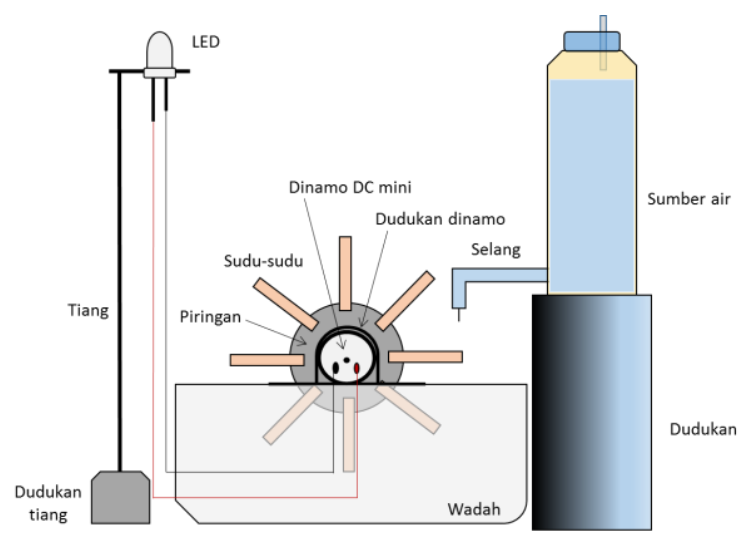

Gambar 3. Desain Proyek STEM Model Pembangkit Energi Listrik Mikrohidro

Gambar 3 menunjukkan desain perakitan komponen KIT menjadi Model Proyek STEM Pembangkit Listrik Mikrohidro. Sumber air berasal dari air dalam wadah yang diposisikan lebih tinggi. Air memutar kincir yang terhubung langsung ke dinamo DC. Selanjutnya, LED akan menyala sebagai indikator adanya arus listrik yang dihasilkan oleh sistem.

\section{Fasa Develop - pemilihan alat dan bahan dan perakitan prototype}

Alat dan bahan diperlukan untuk menghasilkan proyek-proyek STEM. Pada Fasa ini, perakitan KIT dimulai dari pemilihan alat dan bahan yang sesuai dengan keperluan proyek dan sesaui dengan kepentingan pembelajaran. Alat dan bahan proyek STEM siswa dikemas dalam bentuk KIT. KIT STEM Listrik Dinamis SMP dalam hal ini terdiri dari sebuah kotak penyimpanan dan alat serta bahan untuk keperluan proyek. Proyek STEM merupakan proyek yang bisa dibongkar pasang. Pemilihan alat dan bahan telah dilakukan sedemikian rupa sehingga memenuhi kriteria murah, mudah didapat, dapat dipakai berulang-ulang, fleksibel, dan tidak berbahaya. KIT STEM Listrik Dinamis yang telah disiapkan ditunjukkan oleh Gambar 4.

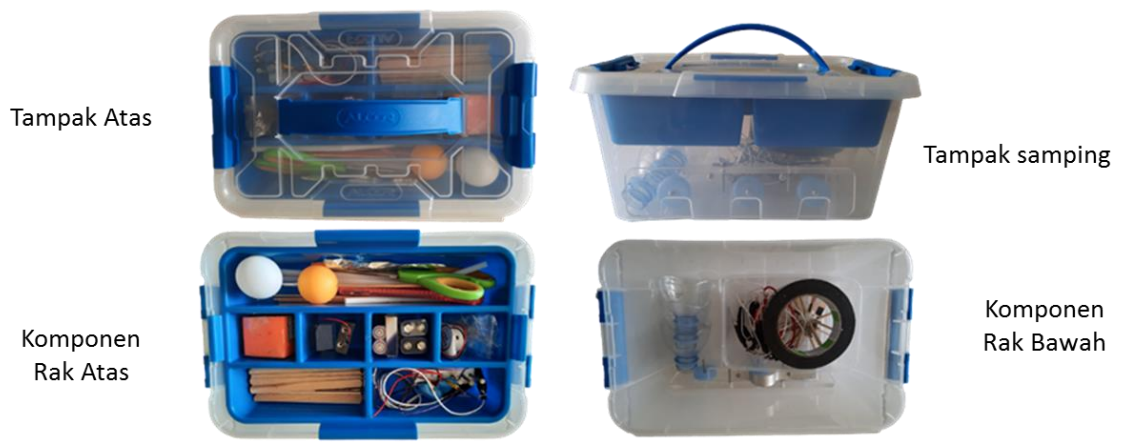

Gambar 4. KIT Proyek STEM Listrik Dinamis SMP 
Gambar 4 menunjukkan KIT STEM Listrik Dinamis SMP. Komponen KIT ditempat dalam rak atas dan rak bawah sehingga memudahkan siswa dalam mengemas KIT setelah dipakai. Pada penelitian ini, peneliti menggunakan berbagai bahan yang harganya relatif murah dan mudah didapat. Bahan-bahan tersebut antara lain: bola pingpong, stik es krim, tusuk sate, sedotan plastik besar dan kecil, kawat penghantar, plastisin, aluminium foil, resistor, LED, dudukan batere, batere 9 Volt, double tip, botol plastik minuman mineral, akrilik, dinamo DC mini, voltmeter digital mini, piringan plastik, buzzer, dan baut, paku kuningan, paku aluminium, dan wadah plastik. Sementara itu, alat yang digunakan dalam merakit proyek adalah gunting, cutter, dan voltmeter. Uji coba awal menemukan bahwa DC voltmeter mini digital tidak membaca tegangan listrik kurang dari 4,5 Volt. Oleh karena itu, alat ukur tegangan listrik menggunakan multi tester. Multitester dapat mengukur tegangan dan arus yang kecil. Tiga proyek yang dapat dibuat menggunakan KIT ini ditunjukkan pada Gambar 5.

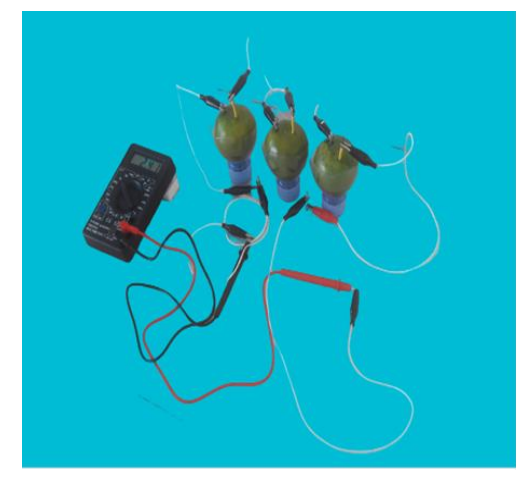

Proyek Eksplorasi Kandungan Eenergi Listrik Buah-buahan

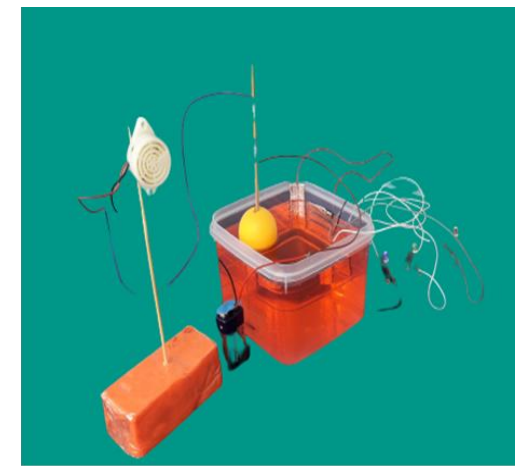

Proyek Model Alarm banjir sederhana

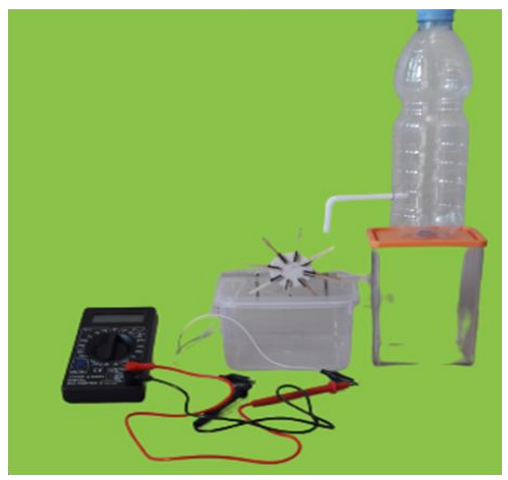

Proyek Model Pembangkit Listrik Mikrohidro

\section{Gambar 5. Contoh Perakitan Proyek STEM Listrik Dinamis SMP}

Gambar 5 menunjukkan contoh perakitan tiga proyek STEM listrik dinamis menggunakan KIT yang telah dibangun sesuai dengan desain yang telah dibuat. Uji fungsi produk dari proyek STEM ini menunjukkan bahwa produk telah berfungsi dengan baik. Untuk Proyek Eksplorasi Kandungan Energi Listrik Buah-buahan, uji coba fungsi produk menunjukkan bahwa alat ukur telah membaca tegangan listrik pada kisaran 0,5 - 1,0 volt untuk setiap satu buah-buahan dan umbi-umbian (jeruk manis, jeruk lemon, dan kentang). Merangkai secara seri buah-buahan tersebut menghasilkan tegangan seri yang lebih besar. Sementara itu, pada Proyek Model Alarm Banjir, menaikkan permukaan air dalam wadah menyebabkan penambahan nyala LED. Ketika permukaan air rendah, maka LED biru yang menyala. Ketika permukaan air naik menjadi setengah wadah, maka LED biru dan hijau menyala. Ketika air naik hampir penuh, maka LED biru, hijau, dan merah akan menyala, serta buzzer berbunyi. Selanjutnya, untuk Proyek Model Pembankit Listrik Mikrohidro, ketika air jatuh ke sudu-sudu kincir, maka kincir berputar dan dinamo mini 
menghasilkan tegangan listrik. Karena tegangan listrik yang dihasilkan relatif kecil sehingga tidak dapat menghidupkan LED, maka peneliti mengganti LED dengan voltmeter digital saku. Semakin tinggi posisi sumber air, maka tegangan listrik yang dihasilkan semakin besar.

\section{Fasa Develop - Validasi Prototype}

Setelah produk dari proyek berfungsi dengan baik, maka selanjutnya prototype KIT Proyek STEM Listrik Dinamis SMP ini divalidasi oleh pakar untuk memastikan kesahan prototype KIT sehingga layak digunakan sebagai media pembelajaran IPA baik secara daring maupun luring. Tiga orang pakar berkualifikasi doktor pendidikan sains dengan pengalaman lebih dari 10 tahun telah memberikan penilaian terhadap KIT proyek STEM ini. Hasil penilaian dari para pakar ditunjukkan oleh Tabel 2.

Tabel 2. Penilaian Pakar Terhadap Prototype KIT Proyek STEM Listrik Dinamis SMP

\begin{tabular}{clcccc}
\hline \multirow{2}{*}{ No } & & \multicolumn{3}{c}{ Skor Rata-Rata Tiap Aspek } \\
\cline { 3 - 6 } & & P1 & P2 & P2 & Rata-Rata \\
\hline 1 & Koherensi dengan kurikulum & 3,60 & 3,40 & 3,60 & 3,53 \\
2 & Interaktif & 3,25 & 3,50 & 3,25 & 3,33 \\
3 & Fleksibilitas & 3,25 & 3,50 & 3,50 & 3,42 \\
4 & Daya tarik visual & 3,50 & 3,75 & 3,50 & 3,58 \\
5 & Kesederhanaan & 3,67 & 3,67 & 3,33 & 3,56 \\
6 & Keamanan & 3,67 & 3,67 & 4,0 & 3,78 \\
7 & Kemudahan & 3,67 & 3,33 & 3,67 & 3,56 \\
\hline & Rata-rata semua aspek setiap pakar & 3,51 & 3,55 & 3,55 & - \\
\hline & Rata-rata semua aspek, semua pakar & - & - & - & 3,54 \\
\hline
\end{tabular}

Tabel 2 menunjukkan bahwa penilaian pakar dilakukan pada tujuh aspek. Ketiga pakar sependapat bahwa prototype KIT Proyek STEM Aplikasi Listrik Dinamis untuk Siswa SMP ini dinyatakan memiliki koherensi yang tinggi dengan kurikulum. Secara umum hal ini dapat diartikan bahwa, KIT dinyatakan sudah sesuai untuk mencapai tujuan pembelajaran. Pada aspek interaktif, pakar menilai bahwa proyek STEM dapat dimodifikasi oleh siswa dan dapat dikerjakan siswa secara mandiri di rumah mapun secara kolaboratif di sekolah. Sementara itu, pakar juga berpendapat bahwa KIT memenuhi unsur fleksibilitas. Hal ini bermakna bahwa, pengerjaan proyek STEM dapat dilakukan dimana saja (tidak harus di sekolah) dan dapat diulang kapan saja di rumah.

Berdasarkan aspek daya tarik visual, Tabel 2 menunjukkan pendapat semua pakar bahwa KIT memberikan kesan yang menarik bagi siswa, baik dari komponen KIT yang digunakan, maupun proyek yang dihasilkan oleh KIT. Para pakar juga sependapat bahwa prototype KIT Proyek STEM Aplikasi Listrik Dinamis untuk siswa SMP sederajat ini telah memenuhi aspek kederhanaan, artinya KIT dibuat dari bahan yang murah dan mudah didapat serta sederhana dari bentuk dan cara kerja komponen. KIT juga dinyatakan memenuhi aspek keamanan yang artinya bahwa KIT tidak membahayakan siswa dalam penggunaannya, seperti tidak mengandung zat beracun, atau mudah terbakar, atau penggunaan listrik bertegangan tinggi. Aspek kemudahan sangat penting dalam penilaian suatu media pembelajaran. Semua pakar sependapat bahwa KIT telah memenuhi unsur kemudahan dalam penggunaannya. KIT dinilai memberikan kemudahan bagi siswa dalam melakukan perakitan proyek dan mengemas kembali KIT, sehingga aktivitas mengerjakan proyek lebih efisien dari segi waktu. 
KIT proyek STEM ini diharapkan mampu mengatasi kendala implementasi STEM di lapangan. Hal ini karena kendala dalam implementasi STEM adalah kurangnya peralatan dan media pengajaran STEM (Ejiwale, 2013). Agar pembelajaran dengan pendekatan STEM dapat diimplementasikan dalam pendidikan dengan baik, maka STEM sebagai disiplin interdisipliner mensyaratkan bahwa pendekatan pedagogis harus diubah dari pendekatan tradisional untuk mendukung pembelajaran siswa (Kennedy \& Odell (2014). Oleh karena itu, peran guru sangat penting dalam pengubahan mindset bahwa pembelajaran harus berorientasi proses dan produk dan bahwa sains, tidak bisa berdiri sendiri terutama dalam mengaplikasikan konsep-konsep sains. Kesulitan guru mengimplementasikan STEM masih merupakan permasalahan yang serius (Thi To Khuyen, et al. 2020). Oleh karena itu, penelitian ini memberikan implikasi verifikasi teori-teori tentang pendekatan STEM dan pada usaha-usaha untuk mengoptimalkan implementasi pendekatan STEM dalam pendidikan sains.

Meskipun prototype KIT Proyek STEM Aplikasi Listrik Dinamis untuk siswa SMP ini telah berhasil didesains dan dibangun serta telah mendapatkan pengesahan (validasi) pakar, namun penelitian ini memiliki keterbatasan diantaranya: KIT masih dalam bentuk prototype, jumlah proyek terbatas, dan baru sampai pada tahap validasi pakar untuk menilai potensi dampak produk sebagai media pembelajaran berbasis proyek STEM. Lebih lanjut lagi, mengetahui bagaimana interaksi siswa dengan produk dan dampak ril produk ini dalam pembelajaran, maka penelitian ini akan dilanjutkan untuk fase impelemntasi dan evaluasi.

\section{SIMPULAN}

Protype KIT Proyek STEM Aplikasi Listrik Dinamis untuk pembelajaran IPA SMP telah didesain, dibangun, dan divalidasi. Prototype KIT telah dinyatakan memenuhi persyaratan media pembelajaran dari aspek kurikulum, interaktif, fleksibiltas, daya tarik, kesederhanaan, keamanan, dan kemudahan oleh pakar pendidikan sains. Oleh karena itu, prototype KIT dinyatakan sah dan layak untuk digunakan dalam pembelajaran IPA, baik secara daring maupun secara luring. Dalam pembelajaran daring, pembimbingan guru dilakukan secara daring menggunakan Learning Management System (LMS) seperti Google Classroom atau menggunakan Video Conference seperti Google Meet, Zoom Meeting, dan lain-lain. Setidaknya terdapat tiga proyek STEM yang dapat dirakit menggunakan KIT ini, diantaranya Proyek Eksplorasi Kandungan Energi Listrik Buah-buahan, Proyek Model Alarm Banjir Sederhana, dan Proyek Model Pembangkit Listrik Mikrohidro.

\section{PENGHARGAAN}

Ucapan terimakasih disampaikan kepada Rektor Universitas Riau yang telah menyediakan dana penelitian ini melalui dana DIPA Universitas Riau tahun 2020. Ucapan terimakasih juga disampaikan kepada Ketua dan seluruh staf LPPM Universitas Riau yang telah memfasilitasi penelitian ini. Semoga penelitian ini memberikan manfaat bagi peningkatan mutu pendidikan IPA di tanah air.

\section{REFERENSI}

Bozkurt Altan, E., \& Ercan, S. (2016). STEM Education Program for Science Teachers: Perceptions And Competencies. Journal of Turkish Science Education, 13(Specialissue), 103117.

Branch, R, B. (2009). Instructional Design: The ADDIE Aproach. New York: Springer. 
Bryan, A \& Volchenkova, K. N. (2016). Blended Learning: Definition, Models, Implications for Higher Education. Bulletin of the South Ural State University Series "Education. Education Sciences," 8(2), 24-30.

Ejiwale, J,A. (2013). Barriers to Successful Implementation of STEM Education. Journal of Education and Learning, 7(2), 63-74.

Gonzalez, H. B., \& Kuenzi, J. (2012). What Is STEM Education and Why Is It Important? Congressional Research Service, (August), 1-15.

Ismail, Permanasari, A., Setiawan, W. (2016). STEM Virtual Lab: An Alternative Practical Media to Enhance Student's Scientific Literacy, Jurnal Pendidikan IP A Indonesia, 5(2), 239-246

Kenndey, T, J \& Odell, M, R, L. (2014). Engaging Students In STEM Education. Science Education International, 25(Issue 3), 246-258

Lalima, D., \& Lata Dangwal, K. (2017). Blended Learning: An Innovative Approach. Universal Journal of Educational Research, 5(1), 129-136.

Murnawianto, S., Sarwanto, S., \& Rahardjo, S. B. (2017). STEM-Based Science Learning in Junior High School: Potency for Training Students' Thinking Skill. Pancaran Pendidikan, 6(4).

Nugroho, O. F., Permanasari, A., \& Firman, H. (2019). The Movement of STEM Education in Indonesia: Science Teachers' Perspectives. Jurnal Pendidikan IP A Indonesia, 8(3), 417-425.

Poon, J. (2013). Blended learning: An institutional approach for enhancing students' learning experiences. Journal of Online Learning and Teaching, 9(2), 271.

Sudjana, N dan Rivai, A.(2019). Media Pengajaran. Jakarta: Sinar Baru Algesindo.

Thi To Khuyen, N., Van Bien, N., Lin, P.-L., Lin, J., \& Chang, C.-Y. (2020). Measuring teachers' perceptions to sustain STEM education development. Sustainability, 12(4), 1-15

Zulirfan, Z, Yennita, Y \& Rahmad, M. (2020). STEM at Home: Provide Scientific Activities for Students During the Covid-19 Pandemic, URICSE(2020), Vol. 1655(2020), IOP Publishing 